\title{
EL TRABAJO COLEGIADO: INDIVIDUALIDADES, RESISTENCIAS Y CONTEXTOS
}

\author{
Florentino Silva-Becerra ${ }^{1}$
}

Fecha de recepción: 4 de noviembre de 2016

Fecha de aceptación: 25 de mayo de 2017

Resumen - En este trabajo se abordan las subjetividades y las pautas de organización de una realidad próxima, desde los espacios colegiados a través del Consejo Técnico Escolar, donde se fortalecen valores, normas y formas de control social que ejerce el grupo dominante, manifestadas en las resistencias y alianzas que tienen como fin el poder. Plantea como problema central el sentido que los profesores y directivos otorgan al trabajo en conjunto realizado en el Consejo Técnico Escolar, teniendo como fin el significado de las interacciones, para conducir dichos espacios colegiados hacia las nuevas tendencias pedagógicas. Se utilizó como método la etnografía y se participó en la dinámica escolar, estableciendo un muestreo teórico mediante la selección de los sujetos que proporcionaron los datos para continuar con el siguiente grupo de informantes y establecer la comparación. Los resultados son enriquecedores para el Cuerpo Académico, esperando como efecto comprender estos contextos escolares "in situ".

\section{Palabras clave:}

Consejo Técnico Escolar, identidad social, interacción social, micropolítica, trabajo colegiado.
Abstract - In this paper subjectivities and patterns of organization a reality next addressed, from the collegiate spaces through the Technical Council School, where are strengthened: values, norms and forms of social control exercised by the dominant group, manifested in resistance and partnerships that aim to power. Central problem posed as meaning that teachers and administrators give the referee work in the Technical School Board, having as its goal the meaning of interactions, to drive collegiate spaces to new educational trends. Using ethnography as method, participating in school dynamics show a theoretical setting by selecting subjects that will provide data for successively proceed to the next group of informants and make the comparison. The results are nutrients for Student Body, waiting as the impact school understand these contexts "in situ".

\section{Keywords:}

Collegial work, social interaction, micro and social identity. 


\section{Introducción}

I trabajo colegiado se lleva acabo en la reunión que los profesores directivos realizan el viernes último de cada mes, con la intención de resolver las problemáticas escolares, utilizando una guía que establece paso a paso el abordaje general de dichos problemas.

Los espacios colegiados propiciados a través del Consejo Técnico Escolar fortalecen valores, normas y formas de control manifestadas en las resistencias y alianzas que se imponen de la minoría sobre la mayoría, esto alienta la unidad y la búsqueda de espacios de poder; es la plataforma para expresar sentimientos que la minoría exterioriza y abandera, lo cual se refleja en la resistencia a la integración laboral de los docentes y directivos, permitiendo el manejo del consenso, vertido en acuerdos que revelan el sentir, estableciendo una barrera para lograr el "no hacer" y ejerciendo la intervención como un primer paso para el logro que sacia su ansia de poder político y reafirma la pertenencia al grupo.

Las oportunidades de interacción, donde el grupo se identifica y se fortalecen los liderazgos, refuerzan sus actuaciones micropolíticas como instrumento de negociación a través de la resistencia ante las nuevas formas de comprensión pedagógica.

Las variadas relaciones de pensamiento que emergen en el contexto dan vida a los sentimientos de poder (el control de la organización escolar) y se convierten en un peldaño que alimenta la estrategia, dando lugar a un movimiento silencioso de resistencia.

\section{La colegialidad y la interacción social}

En la interacción colegiada se construye la concepción de lo social; constituido en las interacciones grupales, "lo social presente en todo encuentro, porque todo encuentro intergrupal supone interactuantes socialmente situados y caracterizados en un contexto que imprime su sello", aportando un conjunto de códigos, normas y modelos que vuelven posible la comunicación y aseguran su relación (Marc y Pichard, 1992).
Es a partir de esta impresión (códigos, normas y modelos) que se manifiesta la concepción del trabajo colegiado y genera un orden social en un ámbito específico, un ámbito local que establece sus reglas ceremoniales y los rituales que gobiernan en las relaciones cara a cara: el orden de la interacción está en la base del orden social (Strong, 1998 y Burns, 1992).

El mencionado orden conduce a la estructuración simbólica de un contrato social en que se inscriben normas y valores que sin estar rubricados por los integrantes del grupo, se aceptan como justos, validados por el consenso colectivo que imprime una forma de entender y actuar. Esta concepción colegiada es compartida por los miembros de manera simbólica, impregna el contexto y otorga sentido a sus acciones.

La teoría de la interacción social concibe a estas situaciones como el producto de la intencionalidad de sus miembros, en la que se robustecen los intereses o motivaciones a través de la contingencia de la acción social (Giglioli, 1989), unida por vínculos normativos, valores, normas, representaciones colectivas y formas de control social que se imponen exteriormente y que condicionan la interacción de sus integrantes.

La relación entre profesores y directivos nutre al "capital cultural", compuesto por el conjunto de competencias lingüísticas y culturales que heredan los individuos por medio de límites establecidos, debido a la clase social inmersos en el habitus que incorpora las disposiciones subjetivas reflejadas en el gusto, conocimiento y conductas inscritas en esquemas de pensamiento de cada persona en desarrollo (Bourdieu y Passeron, 1977; Giroux, 1993).

Este habitus representa el vínculo mediador entre las estructuras de prácticas sociales y las de reproducción. En el sistema de "violencia simbólica" no se impone al oprimido mecánicamente, sino que se aprende en el habitus en todas las estructuras sociales, donde cada persona construye su espacio de dominio.

El enfoque de la teoría del campo desarrollada por Lewin (1936) representa a la interacción como una posición; en él, las variaciones individuales del 
comportamiento humano con relación a la norma son condicionadas por la tensión entre las percepciones que el sujeto tiene de sí mismo y del ambiente psicológico en el que se sitúa, el espacio vital, que es topográfico racional o, como él lo llama, "espacio vital", definido como el ambiente total que existe para la persona.

\section{Metodología}

El método etnográfico guía las acciones de este trabajo, busca el acercamiento a la comprensión de la forma de vida. En la escuela, que es el entorno donde se desarrollan las interacciones, intervienen los actores que se analizan en esta escena, donde las interacciones constituyen lo que hacen y dicen como parte del grupo humano, organizando una conducta que sólo puede ser entendida en el medio donde se produce, porque éstas son realidades humanas que representan el mundo de la vida escolar, de ahí la especificidad de los fenómenos que se manifiestan acerca del acto educativo.

La población es el grupo de profesores y directivos que participan en la dinámica escolar de una escuela secundaria, pero pueden variar de acuerdo con su asistencia al grupo. La muestra se estableció a través de la selección de sujetos, denominada "muestreo teórico", sistema desarrollado a por Glaser y Strauss (1967); en este proceso la teoría emerge de los datos, proporcionando criterios para seleccionar a los siguientes informantes (Strauss y Corbin, 1990), es decir, una "estrategia sucesiva", eligiendo primero algunos sujetos y a partir de ellos los próximos, dando con ello paso al "grupo de comparación". Luego de analizar los resultados se selecciona a los siguientes sujetos que se van integrando a la muestra.

\section{Resultados}

El siguiente fragmento es una entrevista realizada el 6 de marzo de 2016.

¿El colegiado generó las participaciones individuales? Entrevistado: Se realiza con participaciones individuales, hacia una general; es decir, ahorita tenemos la oportunidad de que contamos con compañeros con mucha experiencia, por situaciones laborales, y desembocan su haber y su saber y de marera dinámica por parte de algunos profesores, sobre todo en el turno vespertino, hay muchas personas que participan activamente, en el turno matutino es un poquito más.

¿El contexto genera el predominio de la perspectiva individual?

E: El trabajo colegiado desde la perspectiva de cada uno de ellos en sus diferentes áreas tiene que llegar a un fin en común o a la resolución de un problema o a una meta determinada desde sus diferentes visiones.

¿Las aportaciones se vierten desde la posición individual?

E: Sí, desafortunadamente no hacemos el trabajo realmente, sino la posición de cada uno, es individualista.

Mientras el coordinador de los trabajos expone, ¿los integrantes del colegiado permanecen como espectadores?

E: Es el moderador quien lleva la batuta, se traduce en una exposición de términos y muchas personas sólo permanecen como observadoras hasta que tienen la oportunidad de exponer sus ideas, pero no se concretiza, no se conjunta, no se lleva acabo para llevar algo nuevo, no entran en una equidad, por dar un término.

¿Los esquemas anteriores en que el trabajo se realizaba de forma individual generan una visión de esta manera? E: ¡Síl, el principal es romper sus esquemas propios, muy difícil, cuesta mucho trabajo romper con los esquemas de trabajo de uno mismo; toda la vida ha sido esa frase, es muy especial y proponer algo diferente les cuesta muchísimo; cuesta a todos trabajar en proponerlo, ya no se diga en realizarlo. 


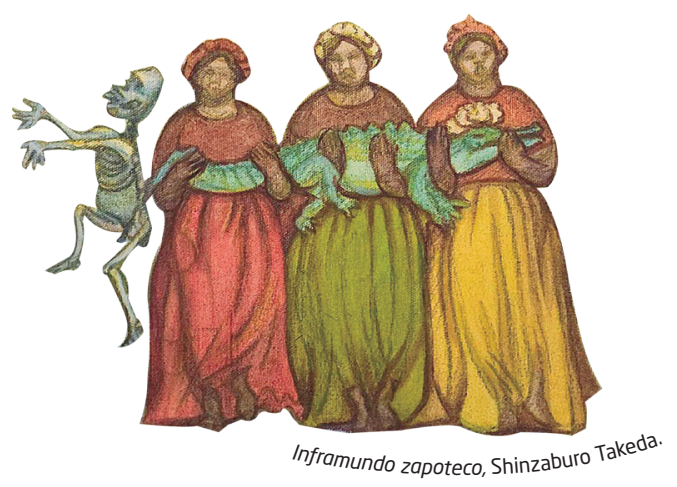

\section{La concepción del colegiado}

¿El trabajo colegiado tiene como fin la resolución de los problemas que afrontan los profesores en el trabajo con los alumnos?

E: El trabajo colegiado desde la perspectiva de cada uno de ellos en sus diferentes áreas se tiene que llegar a un fin en común o a la resolución de un problema o a una meta determinada desde sus diferentes perspectivas.

¿En el desarrollo de los trabajos colegiados no se concretizan las acciones emprendidas?

E: Por lo regular una persona que lleva el movimiento es el moderador es quien lleva la batuta se traduce en una exposición de términos y muchas personas solo permanecen como observadoras hasta que tienen la oportunidad de exponer sus ideas, pero no se concretiza no se conjunta no se lleva acabo para llevar algo nuevo, no entran en una equidad por dar un término.

El trabajo colegiado se realiza ajustado a los horarios de los profesores y éstos sólo cumplen con el horario asignado el día de su realización:

E: Que tienen que estar porque tienen que cubrir su horario, la gran mayoría.

Las temáticas presentadas en el colegiado no nacen del seno del mismo, por lo que muchas de ellas no generan interés:

E: Pero yo considero que los maestros nos quedamos cortos, porque es nada más el directivo hacia los maestros, pero falta todavía dar más espacio, más tiempo y lo de cada quien porque es catártico, porque cada quien explica lo que le pasó en su vida ahí.
¿Las temáticas resultan interesantes si abordan situaciones del contexto de los profesores?

E: ¡Síl, porque ahí viven su experiencia, cómo se sienten y no pasamos de ahí, no hemos tenidos resultados; qué vamos hacer, a ponernos de una forma unísona para llevar acabo determinada actividad con los alumnos y empezar y seguir trabajando todo el siclo escolar con esa premisa, salvo lo que son las competencias, que es la planeación y cuando nos toca la actividad de algún tema en especial es cuando hay movimiento, pero no es en conjunto que hay que exponer.

\section{La micropolítica escolar}

Las posiciones políticas están orientadas por quien dirige los consejos escolares, esto les permite un espacio de manejo de ideas:

E: Sí, desafortunadamente no hacemos el trabajo realmente sino la posición de cada uno, es individualista.

¿Cuando el director asume la dirección del colectivo, los coordinadores pierden su lugar en el colegiado?

E: Mi director ha participado y ha hecho ese movimiento; pierden su lugar, por decir su esquina, los coordinadores cuando está el director en la exposición e interactúa con sus maestros. En las pocas que ha sido así se avanza rápido, pero considero que los maestros nos quedamos cortos, porque es nada más el directivo hacia los maestros, pero falta todavía dar más espacio, más tiempo y lo de cada quien.

\section{Discusión}

Las representaciones colectivas que produce el intercambio de acciones que realizan los sujetos en el 
seno de la vida social constituyen, por lo tanto, hechos sociales que sobrepasan y se imponen al individuo, generando los contextos, pues las propiedades individuales, al sumarse en la colectividad, se convierten en fenómenos eminentemente sociales.

Al respecto, Jodelet (1984, pp. 463, 493) matiza el carácter psicológico de la representación social, al conceptualizarla como "una forma de conocimiento específico, el saber de sentido común, cuyos contenidos manifiestan la operación de procesos generativos y funcionales socialmente caracterizados. En sentido más amplio, designa una forma de pensamiento social".

Entonces, la interacción social deriva de un pensamiento socialmente caracterizado en las relaciones sociales. Durkheim (2000, p. 23) emplea el concepto de representación social para analizar un tipo de fenómeno cuyo origen se encuentra en el entramado de relaciones que establecen los individuos en un determinado grupo, señalando que las representaciones colectivas son "realidades que sostienen con su sustrato íntimas relaciones y cuya autonomía no puede ser sino relativa". Por lo tanto, las relaciones de autonomía de los grupos sociales son producto de los individuos asociados; es decir, constituidos en grupo.

Estas relaciones sociales, de acuerdo con Bourdieu (1977), se convierten en habitus, en una forma de entender la realidad desde la cultura. Este autor lo enuncia así: "sistema adquirido de preferencias, de principios de visión y de división (lo que se suele llamar un gusto), de estructuras cognitivas duraderas (que esencialmente son fruto de la incorporación de estructuras objetivas) y de esquemas de acción que orientan la percepción de la situación y la respuesta adaptada".

El espacio colegiado es una construcción subjetiva donde el poder recrea sus acciones: "todo poder que logra imponer significados e imponerlos como legítimos, disimulando las relaciones de fuerza en que se funda su propia fuerza, añade su fuerza propia, es decir, propiamente simbólica, a esas relaciones (Bourdieu y Passeron, 1977).

\section{Conclusiones}

El mundo de la vida es la fuente de significados que se constituyen y refuerzan a través de la experiencia, porque a través de esta visión los miembros del colegiado distinguen las categorías que integran el grupo al que pertenecen, generando visiones compartidas de la realidad e interpretaciones de su constitución grupal.

La interacción social se deriva de un pensamiento socialmente caracterizado en las relaciones sociales colectivas, producidas por el intercambio de acciones que realizan los individuos en el seno de la vida social; integran, por lo tanto, hechos sociales que sobrepasan y se imponen al individuo, propiciando los contextos, pues las propiedades individuales, al sumarse en la colectividad, se convierten en fenómenos eminentemente psicosociales.

En la escuela se relacionan formas distintas de pensamiento, como son las interacciones grupales por naturaleza social, que generan los espacios de poder, donde cada escuela tiene una organización micropolítica, porque en esta organización se conceptualizan sus intereses, convirtiéndose en una forma de pensamiento que da origen a una ideología que se sacia con la obtención de poder.

\section{Referencias}

Ball, S. (1989). La micropolítica de la escuela: hacia una teoría de la organización escolar. Barcelona: Paidós.

Bourdieu, P. \& Passeron, J. (1977). La reproducción. Elementos para una teoría del sistema de enseñanza. Barcelona: Laia.

Burns, H. (1992). Human Rights in the world Comunity: Issues and action. Philadelphia: University of Pensilvania. 
Durkheim, E. (2000). Representaciones individuales y representaciones colectivas. En Sociología y filosofía (pp. 27-58). Madrid: Miño y Dávila Eds.

Giglioli, P. (1989). Etnometodología. Bolonia: II Molino.

Giroux, H. (1993). La escuela y la lucha por la ciudadanía. México: Siglo XXI.

Glaser, B. G. \& Strauss, A. L. (1967). Discovery of grounded theory. Chicago: Aldine.

Jodelet, D. (1984) La representación social. Fenómenos, concepto y teoría. En S. Moscovici et al (Eds.). Psicología social II. Psicología social y problemas sociales. Barcelona: Paidós.
Lewin, K. (1936). Principles of topological psychology. New York: McGraw-Hill.

Marc y Pichard, D. (1992). Interacción social, cultura, instituciones y comunicación. España: Paidós.

Strauss, A. \& Corbin, J. (1990). Basics of Qualitative Research: Technichiques and procedures for developing grounded theory. Newbury Park CA: Sage Publications.

Strong, P. (1988). Minor Courtesies and Macro structures. En A. Murcott (Ed.), Sociology and Medicine. Selected essays by P. M. Strong (pp. 357376). UK: University of Nottingham.

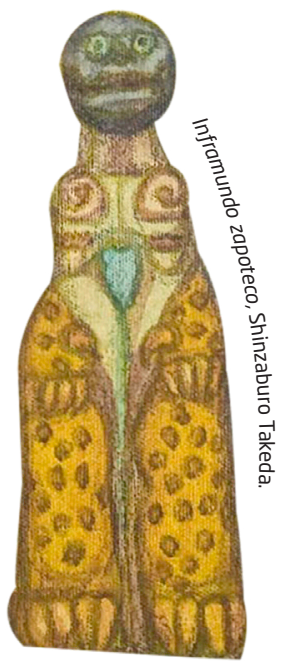

